\title{
Apresentação
}

\section{Pessoa e ambiente, as duas faces da mesma moeda}

As mudanças no sistema pessoa-ambiente ao longo do curso de vida constituem o processo básico do desenvolvimento (Lerner, 1991; Stokols, 1978; Tobach, 1981). Resulta daí a importância de estudar a pessoa em seu contexto. Essa proposição nem sempre foi prevalente na ciência psicológica. A noção de que o ambiente físico exerce um impacto significativo na vida das pessoas tem uma curta história (Sommer, 1966; Wachs, 1990). No campo da psicologia do desenvolvimento o modelo teórico vigente no limiar do século XX enfatizava a genética. Os pesquisadores dedicavam sua atenção aos seres animados, mas deixavam de lado as variáveis relacionadas aos ambientes nos quais as pessoas vivem.

No período compreendido entre 1920 e 1960, como conseqüência do behaviorismo e da teoria da aprendizagem social, o paradigma dominante destacou o papel modelador do ambiente (Bijou \& Baer, 1961; Overton \& Reese, 1973). Entre 1960 e 1980 surgiram novos modelos teóricos que não mais defendiam a influência exclusiva de fatores internos (natureza) ou externos (cultura), ao aceitar o princípio epigenético e a interação entre estrutura e função como o principal determinante do desenvolvimento (Gottlieb, 1991; Lerner, 1991; Lerner, Easterbrooks \& Mistry, 2003).

Paralelamente, outro importante aspecto sofreu alteração: a Psicologia do Desenvolvimento expandiu seu interesse para outras fases do curso de vida (Baltes, Staudinger \& Lindenberger, 1999; Staudinger \& Bluck, 2001). Antes, a teoria e a pesquisa restringiam seus interesses aos anos da infância (Lerner \& Steinberg, 2004; Petersen, 1988), limitando-se a estudar essa fase, sem atentar para o fato de que os processos de desenvolvimento envolvem estabilidade e mudança, transição e crise, ganhos e perdas durante toda a vida. Finalmente, enxergou-se que os adultos também mudam - descobriu-se o desenvolvimento adulto. Assim, avanços teóricos e metodológicos na Psicologia do Desenvolvimento, aliados ao surgimento de um novo campo de estudo, a Psicologia Ambiental, (Proshansky, Ittelson \& Rivlin, 1970; Sime, 1999;
Stokols, 1995) possibilitaram uma maior atenção às variáveis relacionadas ao contexto (Bronfenbrenner \& Morris, 1998) e à diversidade das várias etapas da vida (Baltes, 1987).

Este dossiê inclui produções que exemplificam estudos sobre a interação pessoa-ambiente. Constitui uma expansão de três trabalhos apresentados na Mesa Redonda Desenvolvimento humano e meio ambiente: Cara e coroa? no V Congresso Norte-Nordeste de Psicologia, realizado em Maceió-AL, em maio de 2007. Os trabalhos adotam um quadro de referência bidirecional, investigam como as características das pessoas operam reciprocamente com as características do ambiente e fornecem informações sobre processos de desenvolvimento típicos que têm lugar em ambientes típicos. Cada contribuição focaliza um ambiente diferente, envolve uma faixa etária específica e é motivada por questões distintas.

A primeira dessas questões é endereçada por Mara Campos-de-Carvalho e Tatiana Noronha de Souza, da Universidade de São Paulo, Ribeirão Preto, e tem como título: Psicologia Ambiental, Psicologia do Desenvolvimento e Educação Infantil: Integração possível? Este artigo condensa várias pesquisas que examinam o arranjo espacial em salas de creches de crianças de 1 a 2, 2 a 3 e 3 a 4 anos como um elemento mediador da interação criançacriança e criança-educador; tais estudos evidenciam empiricamente que o arranjo espacial pode favorecer, dificultar ou impedir práticas educativas e interativas, práticas estas que promovem ou dificultam o desenvolvimento e a aprendizagem infantis. Apresenta, também, estudos sobre uma escala estadunidense de avaliação de qualidade de ambientes infantis coletivos e uma análise de princípios de qualidade de tais ambientes apresentados em documentos nacionais e internacionais. Desta maneira, fornece uma nova direção neste importante tema de estudo, por sua contribuição teórica e pela possibilidade de guiar pesquisadores e práticos na diferenciação e integração de questões que 
caracterizam contextos diários do cuidado e da educação infantis.

O segundo artigo, Reflexões sobre o comportamento infantil em um pátio escolar: $O$ que aprendemos observando as atividades das crianças, examina a maneira como crianças entre três e sete anos utilizam diferentes áreas de um pátio escolar. Odara de Sá Fernandes e Gleice Azambuja Elali, da Universidade Federal do Rio Grande do Norte, recorrem, por meio da observação sistemática, ao método de mapeamento comportamental e clarificam como, onde e com quem meninos e meninas de diferentes idades interagem durante o recreio. Esse estudo propicia um estimulante exemplo de como formular questões de pesquisa com o objetivo de investigar a influência da pessoa no contexto e do contexto na pessoa. Características das crianças idade e gênero - em interação com características do ambiente - tamanho, tipo, temperatura demonstram engenhosamente a interação recíproca pessoa-ambiente.

A terceira questão está ligada à ampliação do topo da pirâmide demográfica, cuja visibilidade tem motivado um número crescente de pesquisas com idosos. Ambiente de moradia e controle primário em idosos amplia o estudo da interação pessoaambiente para além dos 60 anos e se detém em questões ligadas ao controle, à autonomia e à privacidade, preocupações reconhecidas dessa faixa etária. Hilma Tereza Tôrres Khoury, da Universidade Federal do Pará, e Isolda de Araújo Günther, da Universidade de Brasília, chamam atenção, por meio dos conceitos de controle primário e controle secundário, de como variações na densidade social afetam o sentimento de privacidade no ambiente de moradia, a percepção de autonomia, de independência e de comando sobre a própria vida e sobre o ambiente.

Os artigos que compõem esse dossiê, além do particular atrativo que podem despertar separadamente, envolvem em seu conjunto três fases do curso de vida e apresentam a pertinência de uma perspectiva teórica que possibilita o estudo da relação recíproca entre a pessoa e seu ambiente.

Isolda de Araújo Günther

\section{Referências}

Baltes, P. B. (1987). Theoretical propositions of lifespan developmental psychology: On the dynamics between growth and decline. Developmental Psychology, 23, 611-626.

Baltes, P. B., Staudinger, U. M., \& Lindenberger, U. (1999). Lifespan psychology: Theory and application to intellectual functioning. Annual Review of Psychology, 59, 471-507.

Bijou, S. W., \& Baer, D. M. (1961). Child Development: A systematic and empirical theory. New York: Appleton-Century-Crofts.

Bronfenbrenner, U., \& Morris, P. A. (1998). The ecology of developmental process. In W. Damon (Series Ed.) \& R. M Lerner (Vol. Ed.), Handbook of child psychology: Vol 1 Theoretical models of human development (5th ed., pp. 993-1028). New York: Wiley.

Gottlieb, G. (1991). Epigenetic systems view of human development. Developmental Psychology, 27(1), 33-34.

Lerner, R. (1991). Changing organism-context relations as the basic process of development: A developmental contextual perspective. Developmental Psychology, 27, 27-32.

Lerner, R. M., Easterbrooks, M. A., \& Mistry, J. (2003). Introduction: Dimensions of developmental psychology. In I. B. Weimer (Editor-in-Chief) \& R. M. Lerner, M. A. Easterbrooks, \& J. Mistry (Vol. Eds.). Handbook of psychology: Vol. 6 Developmental psychology (pp.1-10). New Jersey, NJ: John Wiley \& Sons.

Lerner, R. M., \& Steinberg, L. (2004). The scientific study of adolescent development: Past, present, and future. In R. M. Lerner \& L. Steinberg (Eds.), Handbook of adolescent psychology (2nd ed., pp.1-12). New Jersey, NJ: John Wiley \& Sons.

Overton, W. F., \& Reese, H. W. (1973). Models of development: Methodological implications. In J. R. Nesselroade (Ed.), Life-span developmental psychology: Methodological issues (pp. 65-86). New York: Academic Press. 
Petersen, A. C. (1988). Adolescent development. Annual Review of Psychology, 39, 583-607.

Proshansky, H. M., Ittelson, W., \& Rivlin, L. G. (Eds.). (1970). Environmental psychology: Man and his physical settings. New York: Holt, Rinehart \& Winston.

Sime, J. D. (1999). What is environmental psychology?: Texts, content and context. Journal of Environmental Psychology, 19(2), 191-206.

Sommer, R. (1966). Man's proximate environment. Journal of Social Issues, 22(4), 59-70.

Staudinger, U. M., \& Bluck, S. (2001). A view on midlife development from life-span theory. In M. E. Lachman (Ed), Handbook of midlife development (pp. 3-39). New York: John Wiley \& Sons.

Stokols, D. (1978). Environmental psychology. Annual Review of Psychology, 29, 253-295.

Stokols, D. (1995). The paradox of environmental psychology. American Psychologist, 50, 821-837.

Tobach, E. (1981). Evolutionary aspects of the activity of the organism and its development. In R. M. Lerner \& N. A. Busch-Rossnagel (Eds.), Individuals as producers of their development: A life-span perspective (pp. 37-68). San Diego, CA: Academic Press.

Wachs, T. D. (1990). Must the physical environment be mediated by the social environment in order to influence development?: A further test. Journal of applied Developmental Psychology, 11, 163-178. 